\title{
An intelligent tool for the characterization of anaemic blood and to find the therapeutic effect of erythropoietin using spectral data
}

\author{
S. Djodilatchoumy ${ }^{1}$, N. Rama ${ }^{2}$ and S. Gunasekaran ${ }^{3}$ \\ ${ }^{1}$ Dept. of Computer Sci. \& Applications; ${ }^{3}$ Spectrophysics Res. Lab., Pachaiyappa's College, Chennai-600030, India. \\ ${ }^{2}$ Dept. of Computer Science, Presidency College, Chennai-600005, India. \\ djodilatchoumy@hotmail.com
}

Abstract: Anaemia is a common problem in Chronic Kidney Disease (CKD) leading to substantial morbidity and mortality if untreated. The particular cells of the failing kidney are unable to secrete sufficient erythropoietin, the harmone that stimulates erythropoiesis. Treatment of anaemia with erythropoiesisstimulating agents (ESA) has led to increased quality of life and a reduced cardiovascular risk. Therefore anaemic blood has to be identified and proper treatment has to be given. Though investigations on characterisation of anaemic blood and therapeutic effect of erythropoietin in CKD have been done by many, not much work is done on automation of this investigations. The goal of this study is to train the System (Neural Network [NN]) to identify whether the given blood sample is anaemic blood or not and also to examine prospectively the effect of erythropoietin in anaemic patients using the System which is already trained to identify the anaemic blood.

Keywords: Anaemia, erythropoietin, chronic kidney

disease, neural network.

Introduction

Anaemia (a reduced haemoglobin [Hb] concentration) is a common problem in chronic kidney disease (CKD) leading to substantial morbidity and mortality if untreated. Over the past decade, effective management has become possible using safer intravenous iron preparations and genetically engineered erythropoiesisstimulating agents (ESA). The particular cells of the failing kidney are unable to secrete sufficient erythropoietin, the hormone that initiates erythropoiesis. Anaemia is considered to be present when blood $\mathrm{Hb}$ concentration is reduced to a level below that is necessary for adequate tissue oxygenation. Reference range for a healthy adult female is between $12 \mathrm{~g} / \mathrm{dl}$ and $15 \mathrm{~g} / \mathrm{dl}$ and for an adult male is between $13 \mathrm{~g} / \mathrm{dl}$ and $17 \mathrm{~g} / \mathrm{dl}$. Anaemia of CKD may present with mild breathlessness and exertion, lethargy and tiredness. However, due to its insidious onset, anaemia associated with CKD is often asymtomatic and only picked up upon routine blood analysis. If anaemia is left untreated, it might lead to complications including increased cardiac output leading to cardiac enlargement and heart failure, cognitive impairment, altered menstrual cycles, erectile dysfunction and impaired immune response. Therefore anaemic blood has to be identified and

\begin{tabular}{|c|c|}
\multicolumn{2}{c}{ Table1 } \\
\hline Weight & Value \\
\hline Weight $_{\mathrm{H}_{\mathrm{H}}} 1-1$ & -2.573772 \\
\hline Weight $_{\mathrm{H}} 1-2$ & 1.527504 \\
\hline Weight $_{\mathrm{H}} 1-3$ & 2.687236 \\
\hline Weight $_{\mathrm{H}} 2-1$ & -0.616765 \\
\hline Weight $_{\mathrm{H}} 2-2$ & 0.676592 \\
\hline Weight $_{\mathrm{H}} 2-3$ & 0.798253 \\
\hline Weight $_{\mathrm{H}} 3-1$ & -1.513120 \\
\hline Weight $_{\mathrm{H}} 3-2$ & 1.591244 \\
\hline Weight $_{\mathrm{H}} 3-3$ & 1.168176 \\
\hline Weight $_{\mathrm{H}} 4-1$ & -1.265713 \\
\hline Weight $_{\mathrm{H}} 4-2$ & 0.852691 \\
\hline Weight $_{\mathrm{H}} 4-3$ & 1.125657 \\
\hline Weight $_{\mathrm{H}} 5-1$ & -1.782553 \\
\hline Weight $_{\mathrm{H}} 5-2$ & 1.254370 \\
\hline Weight $_{\mathrm{H}} 5-3$ & 2.085100 \\
\hline Weight $_{\mathrm{HO}} 1-1$ & -7.752414 \\
\hline Weight $_{\mathrm{HO}} 2-1$ & 4.094495 \\
\hline Weight $_{\mathrm{HO}} 3-1$ & 6.809275 \\
\hline
\end{tabular}

"Anaemia"

http://www.indjst.org 2004)

The European Best Practice Guidelines say that anaemia should be investigated in patients with CKD when $\mathrm{Hb}$ level falls below $11.5 \mathrm{~g} / \mathrm{dl}$ in adult females and $13.5 \mathrm{~g} / \mathrm{dl}$ in adult males (Locatelli et al., 2004). Treatement of anaemia with ESA has led to increase the quality of life and reduce the risk of cardio vascular disease. By ESA therapy the need for blood transfusions to correct anaemia is reduced, decreasing the risk of transmission of blood borne viruses, iron overload and sensitization of patients to future transplants. ESAs also have positive impact on exercise capacity, sleep patterns, cognitive function, immune response and sexual function (Dreicher \& Horl, 2004).

Neural network (NN) processes information in a similar way the human brain does. To capture the essence of biological neural systems, an artificial neuron is defined as follows:

1) It receives a number of inputs. Each input comes via a connection that has strength (weight), which corresponds to synaptic efficacy in a biological neuron. Each neuron also has a single threshold value. The weighted sum of inputs is formed, and the threshold subtracted, to compose the activation of the neuron.

2) The activation signal is passed through an activation function to produce the output of the neuron. So, NN can be trained to behave like a doctor in the characterization of diseases (Christos Stergiou \& Dimitrios Siganos, Neural Networks,http:// www.doc.ic.ac.uk/ nd/surprise_96/ journal/vol4/cs11/report.html). Though investigations on characterization of anaemic blood and therapeutic effect of erythropoietin in CKD have been done by many, not much work is done on automation of these investigations. The goal of this study is to train the NN (intelligent system) to identify whether the given blood sample is anaemic or not, across the dose range on $\mathrm{R} 1, \mathrm{R} 2, \mathrm{R} 3, \mathrm{R} 4, \mathrm{R} 5$ where R1, R2, R3, R4, $\mathrm{R} 5$ are intensity ratio parameters (IRP) and also to examine prospectively the effect of erythropoietin in chronic renal failure (CRF) patients using the trained $N N$. $R 1$ is given by $A_{702} / A_{1035}$, the ratio of $\mathrm{N}-\mathrm{H}$ out of plane deformation of protein and $\mathrm{C}-\mathrm{O}$ stretch of $\beta$ anomer. $\mathrm{R} 2$ is given Indian J.Sci.Technol. 


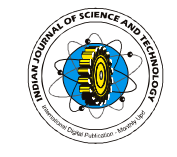

by $A_{1170} / A_{1230}$, the ratio of $\mathrm{C}-\mathrm{O}$ stretch of $\mathrm{COH}$ tyrosine protein and lipid phosphate band arising from the asymmetric $\mathrm{PO}_{2}$ stretching vibration. $R 3$ is given by $A_{1400} / A_{1456}$, the ratio of symmetric and asymmetric bending vibration of the methyl group of protein. $R 4$ is given by $A_{1542} / A_{1655}$, the ratio of the intensities of amide-II and amide-I bands of the amino acids and lipids. $R 5$ is given by $A_{2929} / A_{3300}$, the ratio of intensities of $\mathrm{CH}_{2}$ asymmetric stretching and $\mathrm{N}-\mathrm{H}$ stretching vibration of the secondary amides of the protein (Shaw et al., 1998).

Table 2
\begin{tabular}{|c|c|}
\hline $\begin{array}{c}\text { No. of } \\
\text { neurons in } \\
\text { hidden layer }\end{array}$ & $\begin{array}{c}\text { No. of } \\
\text { iterations }\end{array}$ \\
\hline 2 & 87,293 \\
\hline 3 & 43,931 \\
\hline 4 & 62,686 \\
\hline 5 & 64,521 \\
\hline
\end{tabular}

Vol.2 No. 8 (Aug 2009)

ISSN: 0974- 6846

Table 3. Testing- training samples

\begin{tabular}{|c|c|c|c|c|c|c|c|}
\hline $\begin{array}{c}\text { Sample } \\
\text { No. }\end{array}$ & $\mathrm{R} 1$ & $\mathrm{R} 2$ & $\mathrm{R} 3$ & $\mathrm{R} 4$ & $\mathrm{R} 5$ & $\begin{array}{c}\text { Target } \\
\text { output }\end{array}$ & $\begin{array}{c}\text { System } \\
\text { output }\end{array}$ \\
\hline 1 & 0.613200 & 0.851500 & 1.062900 & 0.653900 & 0.515200 & 0.000000 & 0.000118 \\
\hline 2 & 0.612600 & 0.853000 & 1.077500 & 0.683500 & 0.512700 & 0.000000 & 0.000172 \\
\hline 3 & 0.613100 & 0.850700 & 1.080100 & 0.651300 & 0.520700 & 0.000000 & 0.000164 \\
\hline 4 & 0.610100 & 0.899100 & 1.073300 & 0.684200 & 0.567200 & 0.000000 & 0.000460 \\
\hline 5 & 0.643400 & 0.891300 & 1.062000 & 0.693600 & 0.547600 & 0.000000 & 0.000289 \\
\hline 6 & 0.779600 & 0.954800 & 1.113700 & 0.725300 & 0.621500 & 1.000000 & 0.999782 \\
\hline 7 & 0.769900 & 0.922800 & 1.092500 & 0.722400 & 0.658500 & 1.000000 & 0.999563 \\
\hline 8 & 0.797200 & 0.910300 & 1.137700 & 0.711000 & 0.626200 & 1.000000 & 0.999715 \\
\hline 9 & 0.780100 & 0.914400 & 1.121800 & 0.729000 & 0.617600 & 1.000000 & 0.999746 \\
\hline 10 & 0.775800 & 0.952500 & 1.101600 & 0.740700 & 0.612200 & 1.000000 & 0.999719 \\
\hline 11 & 0.652300 & 0.892900 & 1.064400 & 0.677100 & 0.539000 & 0.000000 & 0.000198 \\
\hline 12 & 0.654300 & 0.897400 & 1.085400 & 0.672900 & 0.518400 & 0.000000 & 0.000417 \\
\hline 13 & 0.630800 & 0.898200 & 1.053300 & 0.694600 & 0.565000 & 0.000000 & 0.000404 \\
\hline 14 & 0.633000 & 0.896700 & 1.057100 & 0.689300 & 0.565400 & 0.000000 & 0.000358 \\
\hline 15 & 0.658300 & 0.892000 & 1.078100 & 0.692200 & 0.512500 & 0.000000 & 0.000470 \\
\hline 16 & 0.801400 & 0.916000 & 1.104400 & 0.732400 & 0.613900 & 1.000000 & 0.999707 \\
\hline 17 & 0.791600 & 0.949300 & 1.101500 & 0.729500 & 0.628800 & 1.000000 & 0.999770 \\
\hline 18 & 0.778300 & 0.921900 & 1.095300 & 0.714700 & 0.623800 & 1.000000 & 0.999548 \\
\hline 19 & 0.772700 & 0.914900 & 1.128000 & 0.756400 & 0.626200 & 1.000000 & 0.999770 \\
\hline 20 & 0.782100 & 0.959100 & 1.104700 & 0.753900 & 0.623000 & 1.000000 & 0.999779 \\
\hline
\end{tabular}

collected from 10 healthy people and 10 anaemic patients between the age group 55 and 70 years from A.K.N. Nursing Homes, Kilpauk,Chennai. The FTIR spectra of blood sera of the collected samples (20 samples) were recorded and fed as input to train our system. The learning parameters ' $\eta$ ' component that is the gradient descent and ' $\alpha$ ' component that is the 'momentum' which effectively keeps a moving average of the gradient descent weight change contributions were carefully chosen to speed up the training. Twenty training samples were repeatedly fed to the system in a random order to minimize the weight oscillations for each of the iteration.

To study the therapaeutic effect of erythropoietin, 10 anaemic patients from A.K.N. Nursing Homes, Kilpauk, Chennai between the age group 55 and 75 year who were suffering from CKD were chosen for the present investigation. Before the drug therapy, their blood samples were collected and FTIR

Experimental description

For characterization of anaemic blood we have used a simple three-layer feed forward back propagation network. During the training iteration of a back propagation $\mathrm{NN}$, we modified the weights at the output layer and then we proceeded backwards on the hidden layer to reach the input layer (Djodilatchoumy et al., 2008). Our system consists of 3 layers namely (i) input layer with 5 neurons, (ii) hidden layer with 3 neurons and (iii) output layer with 1 neuron. The value of the output neuron varies from 0 to 1 (value 0 indicates the most healthy blood and value 1 indicates the most diseased blood). The Weight ${ }_{1 H} \mathrm{x}-\mathrm{y}$ which is the strength/weight of the connection between unit $x$ in the input layer and unit $y$ in the hidden layer and Weight Ho $\mathrm{x}-\mathrm{y}$ which is the weight of the connection between unit $\mathrm{x}$ in the hidden layer and unit $y$ in the output layer are given in Table1.

Two $\mathrm{ml}$ of blood samples were

Research article

CIndian Society for Education and Environment (iSee)
Table 4. Testing- random samples

Sample: 1

Give the input(R1) $\quad-0.5132$

Give the input(R2) - 0.6884

Give the input(R3) - 1.0565

Give the input(R4) $\quad-0.5534$

Give the input (R5) -0.4132 Result- .796272

Sample: 2

Give the input(R1) $\quad 0.8796$

Give the input(R2) $\quad-0.9647$

Give the input(R3) - 1.2232

Give the input(R4) $\quad-0.8253$

Give the input(R5) - 0.6543 Result - .999987

"Anaemia"

http://www.indjst.org

spectra of blood sera of the collected samples are were to our system and the output was noted (preental). The selected 10 patients were prescribed oietin injection 2000 units (drug Erypro) once a week for a period of six months. An interim and final heck up was performed over a period of $3^{\text {rd }}$ and $6^{\text {th }}$ months respectively, after the treatment was initiated. To find the efficacy of the above said drug, the FTIR spectra were recorded at regular interval of 3 months and the spectral data were fed as input to our system and the output were noted down (post- treatmental).

\section{Results and discussion}

The maximum number of iterations that the input samples can be repeated for training is $1,000,000$. The value of ' $\eta$ ' and ' $\alpha$ ' is fixed as 0.9 . Our System will stop learning when the error term that is the difference between network's actual output and the desired output is less than 0.000001 or when it reaches the Indian J.Sci.Technol. 
maximum number of iterations, $1,000,000$. Fixing the value of ' $\eta$ ' and ' $\alpha$ ' value to 0.9 , the network is trained by varying the number of neurons in the hidden layer. We found that our NN is trained effectively with 3 neurons in the hidden layer and the result of which is summarized in Table 2.

Our NN is able to identify the training samples (20) correctly, the result of which is summarized in Table 3. It is also able to identify any random sample correctly which is evidenced by Table 4 .

In order to find the therapeutic effect of erythropoietin, the output of pre-treatment (Pre), post-treatment1 (Post 1), post-treatment 2 (Post 2) are given in Table 5. The \% of therapeutic effect of erythropoietin is calculated using the formula (Pre-Post2) / Pre * 100 and the results are given in Table 6. It is concluded from the result that erythropoietin therapy reduces the disease by $8.5 \%$.

\section{Conclusion}

Neural Networks are being used in the detection of various diseases such as hyperlipidemia, chronic renal failure, head and neck squamous cell carcinoma and a variety of health-related indices can also be monitored (Ronald et al., 2008) The onset of a particular medical condition could be associated with a very complex

Table 5. Therapeutic effect of erythropoietin

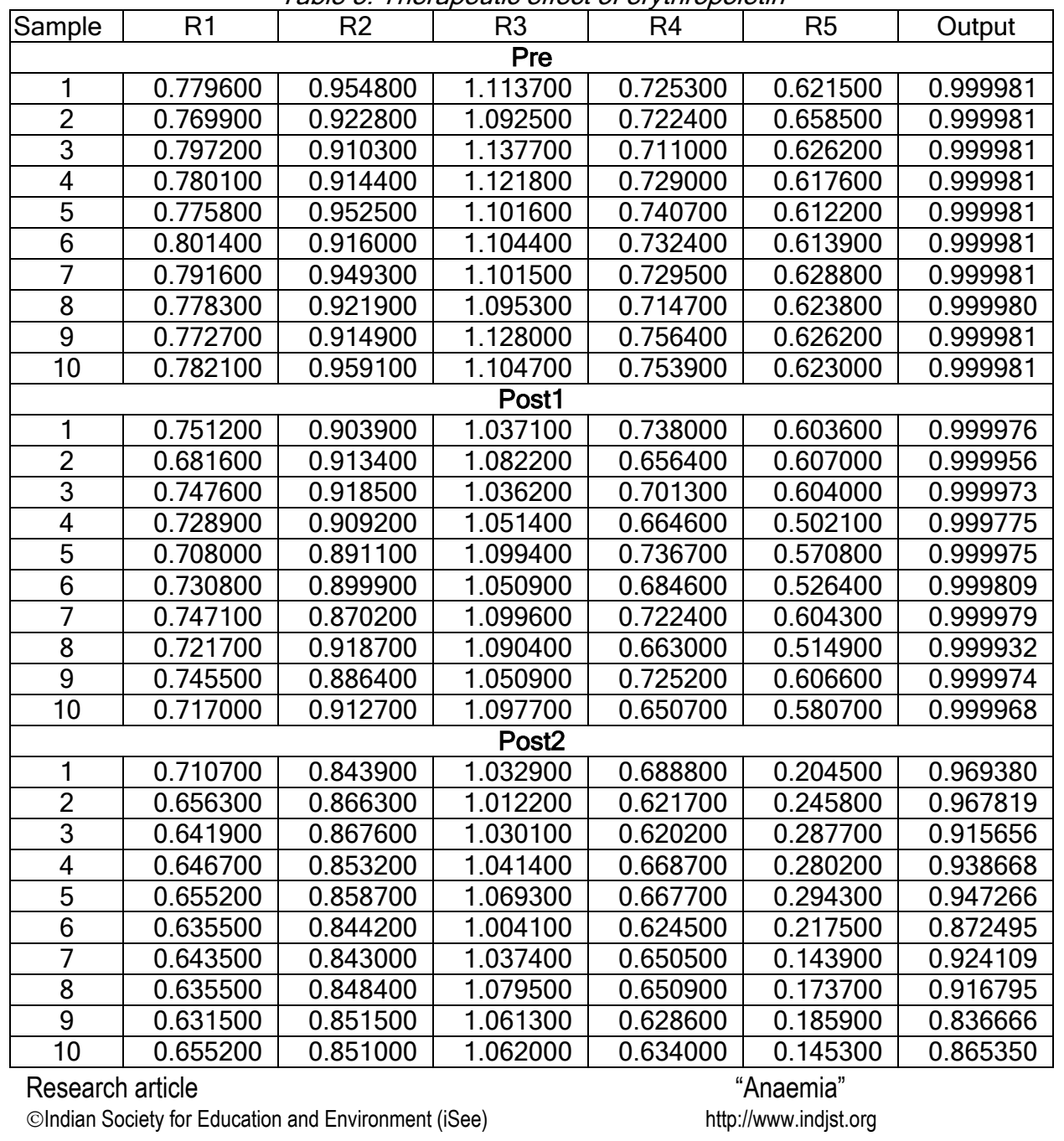

combination of changes on a subset of the variables being monitored in medicines. Neural Networks have been used to recognize this predictive pattern, so that the appropriate treatment can be prescribed. FTIR spectroscopy allows accurate lipids concentration determination. Since our Neural Network is trained to distinguish the anaemic blood with the fine details of FTIR spectra, it can improve the diagnostic accuracy and rate of anaemic treatment at a faster rate with more accuracy. It can also be used to analyze the therapeutic effect of the drug erythropoietin.

Acknowledgement

We are indebted to Dr.K.N.Thirunavukkarasu, A.K.N. Nursing Homes, Kilpauk, Chennai for providing the blood samples of anaemic patients. We are grateful to SAIF, IIT, Chennai for spectral readings.

\section{References}

1. Djodilatchoumy S, Rama N and Gunasekaran S (2008) An intelligent system for the characterization of chronic renal failure blood and study on the efficacy of Simvastatin. Intl. J. Algorithms, Comp.\& Maths. 1(2), 7-12.

2. Dreicher R and Horl WH (2004) Differentiating factors between erythropoiesis-stimulating agents. Drugs. 64, 499-599.

3. Locatelli F, Alijama P, Barany $P$, Canaud B, Carrera F, Eckkardtc $\mathrm{KU}$ et al. (2004) Revised European best practice guidelines for the management of anaemia in patients with chronic renal failure. Nephrol. Dial. Transplant. 19 (Suppl. 2), 1-47.

4. Renal Association: Adult Section 7 (2002) Anaemia in patients with chronic renal failure. Treatement of adults and children with renal failure. Standards and adult measures. $3^{\text {rd }}$ edition. London, Royal College of Physicians. www.renal.org/Standards/RenalSt andards_2002b.pdf

5. Ronald J. Gerstle, Stephen R. Aylward, Sharon Kromhour-Schiro and Suresh K. Mukherji (2000) The role of neural networks in improving the accuracy of MR spectroscopy for the diagnosis of head and neck squamous cell carcinoma, Am. J. Neuroradiol. 21, 1133-1138.

6. Shaw RA, Korawich S, Leroux M and Mantsch H (1998) Multianalyte serum analysis using mid-infra red spectroscopy. Ann. Clin. Biochem. 35, 624-632.

Djodilatchoumy et al. Indian J.Sci.Technol. 